\title{
Cervical arterial dissection: clinical characteristics in a neurology service in São Paulo, Brazil
}

\author{
Dissecção arterial cervical: características clínicas em um serviço de neurologia de São \\ Paulo, Brasil \\ Danyelle Sadala REGES ${ }^{1}$, Marcela MAZZEO², Rafael ROSALINO², Vivian Dias Baptista GAGLIARDI', Leandro \\ Gama CERQUEIRA', Rubens José GAGLIARDI
}

\begin{abstract}
Cervical arterial dissection accounts for only a small proportion of ischemic stroke but arouses scientific interest due to its wide clinical variability. Objective: This study aimed to evaluate its risk factors, outline its clinical characteristics, compare treatment with antiaggregation or anticoagulation, and explore the prognosis of patients with cervical arterial dissection. Methods: An observational, retrospective study using data from medical records on patients with cervical arterial dissection between January 2010 and August 2015. Results: The total number of patients was 41. The patients' ages ranged from 19 to 75 years, with an average of 44.5 years. The most common risk factor was smoking. Antiaggregation was used in the majority of patients (65.5\%); $43 \%$ of all patients recanalized in six months, more frequently in patients who had received anticoagulation $(p=0.04)$. Conclusion: The presence of atherosclerotic disease is considered rare in patients with cervical arterial dissection; however, our study found a high frequency of hypertension, smoking and dyslipidemia. The choice of antithrombotic remains controversial and will depend on the judgment of the medical professional; the clinical results with anticoagulation or antiaggregation were similar but there was more recanalization in the group treated with anticoagulation; its course was favorable in both situations. The recurrence of cervical arterial dissection and stroke is considered a rare event and its course is favorable.
\end{abstract}

Keywords: Stroke; risk factors; primary prevention; secondary prevention; anticoagulants.

\begin{abstract}
RESUMO
As dissecções arterais cervicais correspondem somente a uma pequena proporção dos casos de acidente vascular cerebral (AVC) isquêmico, mas despertam interesse científico devido à sua alta variabilidade clínica. Objetivos: Este estudo destina-se a avaliar os fatores de risco, desfechos clínicos, comparar o tratamento com anticoagulação e antiagregação, e avaliar o prognóstico desses pacientes. Métodos: Estudo observacional, retrospectivo utilizando dados de prontuários de pacientes com dissecção arterial cervical entre os períodos de janeiro de 2010 e agosto de 2015. Resultados: O número de pacientes foi 41 . A idade foi de 19 a 75 anos, com idade média de 44,5 anos.0 fator de risco mais comum encontrado foi o tabagismo. Antiagregação foi utilizada na maioria dos pacientes (65,5\%); $43 \%$ dos pacientes apresentaram recanalização em seis meses, sendo esta mais frequentemente observada nos pacientes que receberam anticoagulação ( $p$ = 0,04). Conclusão: A presença de doença aterosclerótica é considerada rara em pacientes com dissecção arterial cervical. Entretanto, nosso estudo encontrou alta frequência de hipertensão arterial, tabagismo e dislipidemia. A escolha pela terapia antitrombótica permanece controversa e dependerá do julgamento clínico do médico; os resultados clínicos com anticoagulação ou antiagregação foram similares, mas houve maior taxa de recanalização no grupo tratado com anticoagulação. A recorrência de dissecação arterial cervical e AVC foi considerada rara e o curso, favorável.
\end{abstract}

Palavras-chave: Acidente vascular cerebral; fatores de risco; prevenção primária; prevenção secundária; anticoagulantes.

The incidence of stroke increases with age and is less common in people below the age of 45 , with an incidence rate of 7-15 per 100,000 inhabitants per year (ischemic and hemorrhagic) ${ }^{1}$. However, stroke in younger people can have a greater effect on productivity and on reducing quality of life. Although cervical arterial dissection (CAD) is generally among the less common causes of ischemic stroke, being found among the group of non-atherosclerotic arteriopathies,

\footnotetext{
'Irmandade da Santa Casa de Misericórdia de São Paulo, Faculdade de Ciências Médicas da Santa Casa de São Paulo, Departamento de Medicina, Disciplina de Neurologia, São Paulo SP, Brasil;

${ }^{2}$ Faculdade de Ciências Médicas da Santa Casa de São Paulo, São Paulo SP, Brasil.

Rubens Gagliardi (iD) https://orcid.org/0000-0002-3497-0174; Danyelle Sadala Reges iD https://orcid.org/0000-0002-7699-2806; Leandro Gama Cerqueira (iD https://orcid.org/0000-0002-3437-1438; Vivian B. Gagliardi iD https://orcid.org/0000-0003-3182-5147; Marcela Mazzeo iD https:// orcid.org/0000-0002-0484-5559; Rafael Rosalino (iD) https://orcid.org/0000-0003-0351-6144

Correspondence: Danyelle Sadala Reges; Rua Oscar Freire, 1967 / apto 104B; 05409-011 São Paulo SP, Brasil; E-mail: danysadala@yahoo.com.br Conflict of interest: There is no conflict of interest to declare.

Received 10 December 2018; Received in final form 21 February 2019; Accepted 21 June 2019.
} 
it accounts for $20-25 \%$ of cases among younger adults ${ }^{2}$ and is thought to be underdiagnosed ${ }^{1}$. Most of the cases are in individuals under the age of 45 , with a peak of incidence around the age of 40, with men usually suffering around five years later than women ${ }^{3,4}$.

The first clear case of CAD was reported in 1959 in a patient with spontaneous internal carotid artery dissection $(\mathrm{CaAD})^{5}$. However, the spontaneous dissection of the cervical arteries was only fully recognized in the 1970s with the publication by Fisher of a description of its main pathophysiological characteristics ${ }^{6}$. Cervical arterial dissection had been considered rare, but increased awareness of clinical signs and symptoms and the advent of safe and rapid noninvasive imaging methods have made its diagnosis more frequent ${ }^{7}$.

In a population study conducted in Minnesota, the annual incidence of $\mathrm{CaAD}$ was 1.72 per 100,000 people; The combined annual incidence was 2.6 per $100,000^{8}$. Despite this and other similar epidemiological studies ${ }^{7,9}$, the actual incidence of this pathology is still unknown. In Brazil, two case series were published, based on the clinical experience of three tertiary health centers, and produced estimates similar to those produced internationally ${ }^{10,11}$.

Cervical arterial dissection can be related to atherosclerotic disease and thus affects older individuals, especially when it compromises their intracranial segments, and it may also be related to other factors that are still little known. Although studies have identified a number of these potential risk factors associated with $\mathrm{CAD}^{3,10,11,12,13}$, there still needs to be further work in this area.

This study evaluates the epidemiological characteristics of $\mathrm{CAD}$ and its main causal factors, as well as compares treatment with antiaggregation or anticoagulation and the prognosis for patients with $\mathrm{CAD}$. We evaluate how the clinical applicability of this knowledge can help to increase diagnostic accuracy and provide a theoretical basis for conducting future studies.

\section{METHODS}

An observational, retrospective study based on data obtained from the records of patients with $\mathrm{CAD}$ at followup at a vascular neurology referral service in the city of São Paulo, Brazil, from January 2010 to August 2015.

The following data were collected from the records: epidemiological data; clinical data on the initial clinical presentation, the characteristics of the dissection, and the vessels affected; information on related risk factors; whether the patient underwent venous thrombolysis; type of drug treatment (antiaggregation vs. anticoagulation); type of surgical treatment; the National Institutes of Health Stroke Scale (NIHSS) and modified Rankin scale scores at the stroke event and after six months; the incidence of recanalization in six months and the recurrence of stroke in six months.
The information that was not obtained through the medical records review was complemented during the medical consultations of the patients at the outpatient follow-up.

Four-hundred and thirty medical records were reviewed and, after applying the inclusion and exclusion criteria, the total number of patients in the sample was 41 (9\%). The patients were divided into two groups: dissection of the internal carotid artery and dissection of the vertebral artery.

The inclusion criteria were patients who had a CAD diagnosis confirmed by digital angiography, computed tomography angiography or magnetic resonance imaging of the intracranial and cervical vessels within one month of the onset of symptoms. Patients who did not have their diagnosis confirmed through imaging examinations were excluded from this study. All patients were investigated with electrocardiogram, transthoracic echocardiography and study of intracranial and cervical vessels to exclude other causes of stroke.

Stroke severity was assessed using the NIHSS scale, being divided into groups classified as mild with scores of $0-4$, moderate $=5-17$, severe $=18-22$, and very severe $>22$. The modified Rankin scale was also applied with patients being classified as: $0-2=$ good functional outcome, $3-5=$ poor functional outcome, and $6=$ death.

The data input into MS-Excel and the statistical package Statistical Package for Social Sciences (IBM SPSS) version 23.0 were used to obtain the results. We used the following tests: likelihood ratio test and Mann-Whitney U test to verify possible differences between both groups, and Fisher's exact test to verify the degree of relationship between the variables. In the statistical analyses, the significance level of $5 \%(0.05)$ was adopted.

The study was approved by the Research Ethics Committee of the Santa Casa Institution of São Paulo. The patients were informed about the research, and signed an informed consent form before being admitted to the study.

\section{RESULTS}

The patients' ages ranged from 19 to 75 years, with an average of 44.5 years. The analysis of the epidemiological profile regarding sex, race and profession is shown in Table 1. In $56 \%$ of the patients, the dissection occurred in the vertebral artery and $43.9 \%$ in the carotid artery.

The most frequent risk factor in this sample was smoking with $53.6 \%$, followed by hypertension with $46.3 \%$ and dyslipidemia with $19.5 \%$. In $26.82 \%$ of the patients, no risk factors for atherosclerotic disease were identified, as described in Table 2.

Regarding the presence of an associated triggering factor, most of the patients $(61 \%)$ did not have any triggering factors reported within the 24 hours prior to the event. The only associated factor was the presence of mild trauma (38\%). 
Regarding the clinical manifestations, we observed that vertigo was the most frequent initial symptom in the sample. There was statistical significance in the comparison between the groups for these variables: vertigo and motor deficit with $\mathrm{p}<$ 0.001 (Table 3). The most frequent admission NIHSS score range was $0-4$ in $57.5 \%$ of the patients (mild stroke), and the modified Rankin Scale score on admission was $0-2$ in $72.5 \%$ of patients.

The Figure shows the distribution of complications found in the patients in this study, with ischemic stroke being the most frequent complication in $90 \%$ of patients followed by arterial occlusion found in $55 \%$ of patients.

Antiaggregation was used as a treatment in 27 patients, and anticoagulation was performed in 14 patients. The time to begin therapy of choice was up to two weeks according to the clinical severity and the behavioral risks of the proposed therapy. Within six months of the event, $43.3 \%$ of patients recanalized. The comparative analysis between the established clinical treatment and the frequency of recanalization

Table 1. Analysis of the epidemiological profile regarding the sex, race and profession of patients with CAD and comparison between the CaAD and VAD groups.

\begin{tabular}{|c|c|c|c|c|c|c|c|}
\hline \multirow{3}{*}{ Category } & \multicolumn{4}{|c|}{ Group } & \multirow{2}{*}{\multicolumn{2}{|c|}{ Total }} & \multirow{3}{*}{$p$-value } \\
\hline & \multicolumn{2}{|c|}{ Vertebral } & \multicolumn{2}{|c|}{ Carotid } & & & \\
\hline & Frequency & Percent & Frequency & Percent & Frequency & Percent & \\
\hline \multicolumn{8}{|l|}{ Sex } \\
\hline $\mathrm{F}$ & 11 & $47.8 \%$ & 11 & $61.1 \%$ & 22 & $53.6 \%$ & \multirow{2}{*}{0.397} \\
\hline M & 12 & $52.2 \%$ & 7 & $38.9 \%$ & 19 & $46.3 \%$ & \\
\hline \multicolumn{8}{|l|}{ Ethnicity } \\
\hline White & 10 & $45.5 \%$ & 10 & $58.8 \%$ & 20 & $50.0 \%$ & \multirow{3}{*}{0.709} \\
\hline Black & 5 & $22.7 \%$ & 3 & $17.6 \%$ & 8 & $20.0 \%$ & \\
\hline "Pardo" & 7 & $31.8 \%$ & 4 & $23.5 \%$ & 11 & $27.5 \%$ & \\
\hline \multicolumn{8}{|c|}{ Physical demands of job } \\
\hline Light & 18 & $81.8 \%$ & 8 & $47.1 \%$ & 26 & $63.4 \%$ & \multirow{3}{*}{0.026} \\
\hline Moderate & 3 & $13.6 \%$ & 9 & $52.9 \%$ & 12 & $29.3 \%$ & \\
\hline Heavy & - & - & - & - & - & - & \\
\hline
\end{tabular}

*Pardo: ethnic/skin color category, commonly used to refer to Brazilians of mixed ethnic ancestries. CAD: cervical arterial dissection; CaAD: carotid artery dissection; VAD: vertebral artery dissection.

Table 2. Frequency of risk factors for atherosclerosis in the total number of patients with CAD and comparison of these risk factors in the VAD and CaAD groups.

\begin{tabular}{|c|c|c|c|c|c|c|c|}
\hline \multirow{3}{*}{ Variable } & \multicolumn{4}{|c|}{ Group } & \multirow{2}{*}{\multicolumn{2}{|c|}{ Total }} & \multirow{3}{*}{$p$-value } \\
\hline & \multicolumn{2}{|c|}{ Vertebral } & \multicolumn{2}{|c|}{ Carotid } & & & \\
\hline & Frequency & Percent & Frequency & Percent & Frequency & Percent & \\
\hline Smoker & 12 & $52.2 \%$ & 10 & $55.6 \%$ & 22 & $53.6 \%$ & 0.829 \\
\hline Dyslipidemia & 7 & $30.4 \%$ & 1 & $5.6 \%$ & 8 & $19.5 \%$ & 0.046 \\
\hline Uric acid & 1 & $4.3 \%$ & 0 & $0.0 \%$ & 1 & $2.4 \%$ & 0.370 \\
\hline Obesity & 2 & $8.7 \%$ & 1 & $5.6 \%$ & 3 & $7.3 \%$ & 0.702 \\
\hline Hypertension & 11 & $47.8 \%$ & 8 & $44.4 \%$ & 19 & $46.3 \%$ & 0.829 \\
\hline Diabetes & 3 & $13.0 \%$ & 1 & $5.6 \%$ & 4 & $9.8 \%$ & 0.423 \\
\hline Metabolic syndrome & 2 & $8.7 \%$ & 1 & $5.6 \%$ & 3 & $7.3 \%$ & 0.702 \\
\hline None & 7 & $30.4 \%$ & 4 & $22.2 \%$ & 11 & $26.8 \%$ & 0.556 \\
\hline
\end{tabular}

CAD: cervical arterial dissection; CaAD: carotid artery dissection; VAD: vertebral artery dissection.

Table 3. Initial clinical symptoms in patients with cervical arterial dissection.

\begin{tabular}{|c|c|c|c|c|c|c|c|}
\hline \multirow{3}{*}{ Variable } & \multicolumn{4}{|c|}{ Group } & \multirow{2}{*}{\multicolumn{2}{|c|}{ Total }} & \multirow{3}{*}{$\mathrm{p}$-value } \\
\hline & \multicolumn{2}{|c|}{ Vertebral } & \multicolumn{2}{|c|}{ Carotid } & & & \\
\hline & Frequency & Percent & Frequency & Percent & Frequency & Percent & \\
\hline Cervical pain & 5 & $22.7 \%$ & 1 & $5.6 \%$ & 6 & $15.0 \%$ & 0.130 \\
\hline Headache & 3 & $13.6 \%$ & 3 & $16.7 \%$ & 6 & $15.0 \%$ & 0.789 \\
\hline Vertigo & 10 & $45.5 \%$ & 0 & $0.0 \%$ & 10 & $25.0 \%$ & 0.001 \\
\hline Syncope & 1 & $4.5 \%$ & 0 & $0.0 \%$ & 1 & $2.5 \%$ & 0.360 \\
\hline Ataxia & 1 & $4.5 \%$ & 0 & $0.0 \%$ & 1 & $2.5 \%$ & 0.360 \\
\hline Sensibility deficit & 1 & $4.5 \%$ & 0 & $0.0 \%$ & 1 & $2.5 \%$ & 0.360 \\
\hline Diplopia & 1 & $4.5 \%$ & 0 & $0.0 \%$ & 1 & $2.5 \%$ & 0.360 \\
\hline Motor deficit & 0 & $0.0 \%$ & 9 & $50.0 \%$ & 9 & $22.5 \%$ & $<0.001$ \\
\hline
\end{tabular}


at six months showed that recanalization at six months was greater in patients who received anticoagulation than those who received antiaggregation (70\% and 30\%, respectively), with statistical significance $(\mathrm{p}<0.05)$, as shown in Table 4.

When analyzing the relationship between the kind of clinical treatment and the functional outcome after six months, the there were no statistically significant differences between the group that received antiaggregation, and the group that received anticoagulation, with both having good functional outcomes (Table 5).

\section{DISCUSSION}

In this study, we found a $9 \%$ incidence of $\mathrm{CAD}$ at the vascular neurology outpatient clinic. One explanation for this low incidence may be the fact that patients of all ages were included in this analysis and also because only patients with symptomatic CAD were included, which probably underestimated the actual prevalence of the disease.

Cervical arterial dissection is typically a cause of stroke in younger people, but it can occur at any age. In a

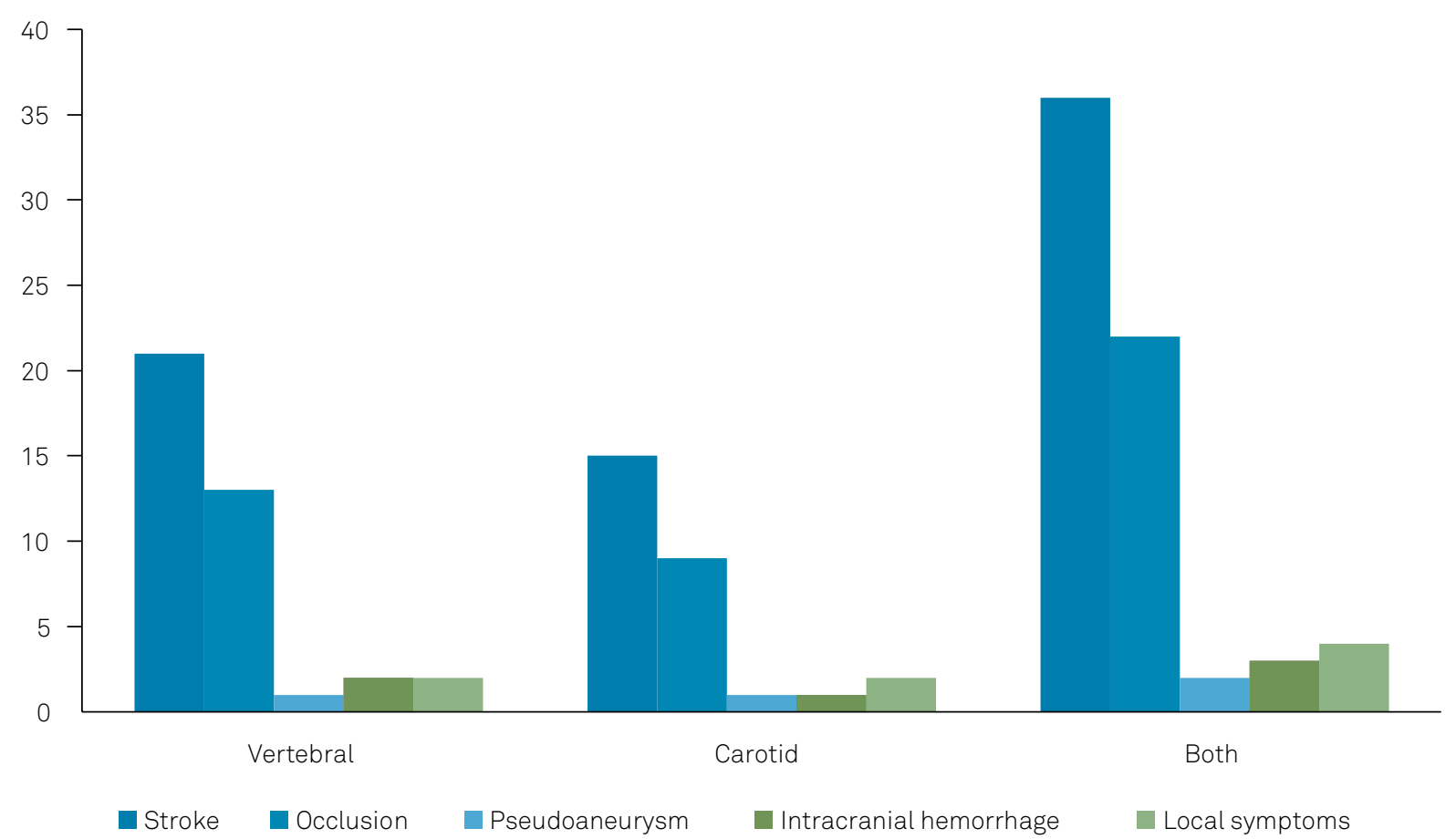

Figure. Distribution of the complications in patients with cervical arterial dissection.

Table 4. Analysis of the relationship between the kind of clinical treatment and the frequency of recanalization in six months in patients with cervical arterial dissection.

\begin{tabular}{|c|c|c|c|c|}
\hline \multirow{2}{*}{ Group } & \multirow{2}{*}{ Recanalization after six months } & \multicolumn{2}{|c|}{ Clinical treatment } & \multirow{2}{*}{$p$-value } \\
\hline & & Antiaggregation & Anticoagulation & \\
\hline \multirow{2}{*}{ Vertebral } & No & $6(35.3 \%)$ & $3(17.6 \%)$ & \multirow{2}{*}{0.419} \\
\hline & Yes & $4(23.5 \%)$ & $4(23.5 \%)$ & \\
\hline \multirow{2}{*}{ Carotid } & No & $8(61.5 \%)$ & $0(0.0 \%)$ & \multirow{2}{*}{0.035} \\
\hline & Yes & $2(15.4 \%)$ & $3(23.1 \%)$ & \\
\hline \multirow{2}{*}{ Total } & No & $14(63.6 \%)$ & $3(30.0 \%)$ & \multirow{2}{*}{0.045} \\
\hline & Yes & $6(30.0 \%)$ & $7(70.0 \%)$ & \\
\hline
\end{tabular}

Table 5. Analysis of the relationship between the kind of clinical treatment and the modified-Rankin scale score in six months in patients with cervical arterial dissection.

\begin{tabular}{|c|c|c|c|c|}
\hline \multirow{2}{*}{ Group } & \multirow{2}{*}{ Rankin in six months } & \multicolumn{2}{|c|}{ Clinical treatment } & \multirow{2}{*}{$p$-value } \\
\hline & & Antiaggregation & Anticoagulation & \\
\hline \multirow{2}{*}{ Vertebral } & $0-2$ & $13(59.1 \%)$ & $8(36.4 \%)$ & \multirow{2}{*}{0.409} \\
\hline & $3-5$ & $0(0.0 \%)$ & $1(4.5 \%)$ & \\
\hline \multirow{2}{*}{ Carotid } & $0-2$ & $11(61.1 \%)$ & $5(27.8 \%)$ & \multirow{2}{*}{0.510} \\
\hline & $3-5$ & $2(11.1 \%)$ & $0(0.0 \%)$ & \\
\hline \multirow{2}{*}{ Total } & $0-2$ & $24(60.0 \%)$ & $13(32.5 \%)$ & \multirow{2}{*}{0.724} \\
\hline & $3-5$ & $2(5.0 \%)$ & $1(2.5 \%)$ & \\
\hline
\end{tabular}


study that evaluated the epidemiological profile and risk factors for CAD in 126 patients, a mean age of 43.2 years was found, with individuals in the $\mathrm{CaAD}$ group being slightly older on average compared with the vertebral artery dissection (VAD) group (43.6 versus 42.6) 3 $^{3}$. Other similar retrospective studies ${ }^{7,8,14}$ found an average age of around 45 years. In a Brazilian study published in $2004^{10}$, the mean age was much lower (37.9 years), again with individuals in the CaAD group being older (38.5 years versus 36.3 years).

In the present study, we found a mean age similar to that described in the literature (44.5 years). The majority of the cases of both CaAD and VAD were in patients older than 40 years. This may be associated with vascular changes acquired throughout life, culminating in the occurrence of $\mathrm{CAD}$ at an age above 40 years ${ }^{15}$. We suggest that $\mathrm{CAD}$ may be a frequent cause of stroke in the non-young adult and that it often underdiagnosed at more advanced ages.

In relation to gender, a higher prevalence was found in women, but when the groups were evaluated separately, men were more prevalent in the VAD group. The literature has reported no clear predominance of sex in $C A D^{16}$.

In the present study, VAD cases predominated with 23 patients (56\%), which differs from the literature on CAD: the extracranial segment of the internal carotid artery is the most commonly affected site, followed by the extracranial segment of the vertebral artery ${ }^{16}$. In a populational study with 982 patients, the incidence of CaAD was nearly two times greater than the incidence of VAD. This has also been demonstrated in other observational studies on the topic ${ }^{3,10}$. However, in a randomized study in 2015 with a sample of 250 patients, the results were similar to those of this study, with VAD prevailing $(53 \%)^{17}$.

The recognition of etiological factors is fundamental to a better understanding of dissections, and to choosing the best secondary prevention. The most frequent risk factor for atherosclerosis in this sample was smoking (53.6\%), followed by arterial hypertension (46.3\%) and dyslipidemia (19.5\%). These results were similar to those found in a study that evaluated the epidemiological profile and risk factors for CAD in 126 patients, in whom dyslipidemia, smoking and hypertension were the most frequently found $(40 \%, 40 \%$ and $25 \%$, respectively) ${ }^{3}$ and in another study with a sample of 965 patients (smoking 49\%, hypertension $28 \%$ and dyslipidemia $20 \%)^{13}$. In the two Brazilian studies already mentioned, the results were also similar ${ }^{10,11}$.

In the present study, no risk factor for atherosclerotic disease was identified in $26.8 \%$ of the patients, with $22.2 \%$ being in the CaAD group and $30.4 \%$ in the VAD group. The fact that fewer patients presented a risk factor for atherosclerosis in the $\mathrm{CaAD}$ group may indicate that the pathophysiology and factors related to $\mathrm{CAD}$ may be different for the vertebral artery and carotid artery ${ }^{18}$. However, there was no statistical significance in the comparison of these data.
The likelihood of risk factors for atherosclerotic disease being present in patients with $\mathrm{CAD}$ has, until recently, been considered low, mainly because atherosclerosis is infrequent in younger individuals, and it is this group that suffers most from CAD. However, studies that evaluated the epidemiological characteristics and risk factors in these patients found a high frequency of hypertension, smoking and dyslipidemia in their samples ${ }^{3,10,11,13,15,17}$.

In their study, Shin et al. ${ }^{15}$ found that age and a history of hypertension were independent predictors of intracranial VAD, concluding that atherosclerosis was related to arterial stiffness and, consequently, would increase the stress on the vessel wall making it more susceptible to $\mathrm{CAD}$.

In agreement with other studies ${ }^{3,10,17,18}$, we found that the complaint of pain was the most frequent initial symptom (12 patients, six with headache and six with cervical pain), with the cervical pain symptom being more frequent in the VAD group and the headache symptom more common in the $\mathrm{CaAD}$ group. In the literature, the frequency of headache varied between 55 and $95 \%^{3,16,18}$. In the VAD group, the most frequent symptom was dizziness, and in the $\mathrm{CaAD}$ group it was language deficit and motor deficit, with these manifestations being the most frequent complication of CAD in this study (corroborating other similar studies), that being stroke ${ }^{3,11,17}$.

This complication is more commonly associated with the occurrence of severe ischemic events than with stenotic dissections $^{12,19}$. However, in the present study, despite the high incidence of this complication, most patients showed low scores on the NIHSS Scale and on the modified Rankin Scale.

The treatment of $\mathrm{CAD}$ remains controversial ${ }^{20}$. In our study, the use of antiaggregation therapy was preferred over the use of anticoagulants (65.8\% versus $34.1 \%$ ). However, reviews on the subject described anticoagulation as typically being used more to prevent new events ${ }^{16,20,21}$. Some authors who advocated the use of anticoagulants in CAD saw this as analogous to their use in cardioembolic stroke.

In the service in which the present study was performed, the preference for antiaggregation may have been due to: better therapeutic adherence, as anticoagulation requires more frequent consultations that may not always be achieved; due to the initial lack of knowledge of the etiology of the stroke, as in some cases the radiological study of the vessels is not performed at admission; and also because of the preference of the medical professionals, mainly due to the safety of this medication in relation to the risk of excessive bleeding associated with anticoagulation.

The Cervical Artery Dissection in Stroke Study (CADISS) trial was the first randomized clinical trial to compare the efficacy of anticoagulation with antiaggregation treatment in preventing the recurrence of stroke and death. No statistically significant differences were found between the two treatments ${ }^{17}$.

In our study, the comparative analysis between the established clinical treatment and the frequency of recanalization 
at six months showed that recanalization at six months was greater in patients who received anticoagulation than those who received antiaggregation (23.3\% and 20\%, respectively), and was statistically significant $(\mathrm{p}<0.05)$. A similar result was found in the study by Pieri et al. ${ }^{11}$, in which $58 \%$ of patients who received anticoagulation in the first six months had a higher rate of recanalization. Although there was no randomization, these data deserve further evaluation in new studies.

Functional outcome after six months was good in both groups. These data reinforce what many studies have shown: that the course of dissections is favorable, with low scores on the NIHSS scale being one of the predictors of a good prognosis $^{12,22}$.

The main limitation of this study relates to the collection of information through medical records, as a lot of information was incomplete or omitted, and incomplete follow-up (only 30 of the 41 patients had a six-month follow-up). More prospective and randomized studies are needed to assess the actual incidence, risk factors and the best treatment of CAD.

\section{References}

1. Wolfe CD, Giroud M, Kolominsky-Rabas P, Dundas R, Lemesle M, Heuschmann P, et al.; European Registries of Stroke (EROS) Collaboration. Variations in stroke incidence and survival in 3 areas of Europe. Stroke. 2000 Sep;31(9):2074-9. https://doi.org/10.1161/01.STR.31.9.2074

2. Griffiths D, Sturm J. Epidemiology and etiology of young stroke. Stroke Res Treat.

3. Dziewas R, Konrad C, Dräger B, Evers S, Besselmann M, Lüdemann P, et al. Cervical artery dissectionDclinical features, risk factors, therapy and outcome in 126 patients. J Neurol. 2003 Oct;250(10):1179-84. https://doi.org/10.1007/s00415-003-0174-5

4. Chaves C, Estol C, Esnaola MM, Gorson K, O'Donoghue M, De Witt LD, et al. Spontaneous intracranial internal carotid artery dissection: report of 10 patients. Arch Neurol. 2002 Jun;59(6):977-81. https://doi.org/10.1001/archneur.59.6.977

5. Anderson RM, Schechter MM. A case of spontaneous dissecting aneurysm of the internal carotid artery. $J$ Neurol Neurosurg Psychiatry. 1959 Aug;22(3):195-201. https://doi.org/10.1136/jnnp.22.3.195

6. Fisher CM, Ojemann RG, Roberson GH. Spontaneous dissection of cervico-cerebral arteries. Can J Neurol Sci. 1978 Feb;5(1):9-19. https://doi.org/10.1017/S0317167100024690

7. Lee VH, Brown RD Jr, Mandrekar JN, Mokri B. Incidence and outcome of cervical artery dissection: a populationbased study. Neurology. 2006 Nov;67(10):1809-12. https://doi.org/10.1212/01.wnl.0000244486.30455.71

8. Schievink WI, Mokri B, Whisnant JP. Internal carotid artery dissection in a community. Rochester, Minnesota, 1987-1992. Stroke. 1993 Nov;24(11):1678-80. https://doi.org/10.1161/01.STR.24.11.1678

9. Schievink WI, Roiter V. Epidemiology of cervical artery dissection. In: Baungartner RW, Bogousslavsky J, Caso V, Paciaroni M, eds. Handbook on cerebral artery dissection. Basel: Fontiers of Neurology and Neuroscience; 2005. Front Neurol Neurosci. 2005. P 12-5.

10. Campos CR, Evaristo EF, Yamamoto FI, Puglia P Jr, Lucato LT, Scaff M. [Spontaneous cervical carotid and vertebral arteries dissection: study of 48 patients]. Arq Neuropsiquiatr. 2004 Jun;62(2b 2B):492-8. Portuguese. https://doi.org/10.1590/S0004-282X2004000300021

11. Pieri A, Spitz M, Valiente RA, Avelar WM, Silva GS, Massaro AR. [Spontaneous carotid and vertebral arteries dissection in a multiethnic population]. Arq Neuropsiquiatr. 2007 Dec;65(4a 4A):1050-5. Portuguese. https://doi.org/10.1590/S0004-282X2007000600029

12. Weimar C, Kraywinkel K, Hagemeister C, Haass A, Katsarava Z, Brunner F, et al. Recurrent stroke after cervical artery dissection.
J Neurol Neurosurg Psychiatry. 2010 Aug;81(8):869-73. https://doi.org/10.1136/jnnp.2009.192153

13. Lichy C, Metso A, Pezzini A, Leys D, Metso T, Lyrer P, et al. Predictors of delayed stroke in patients with cervical artery dissection. Int J Stroke. 2015 Apr;10(3):360-3. https://doi.org/10.1111/j.1747-4949.2012.00954.x

14. Smith WS, Johnston SC, Skalabrin EJ, Weaver M, Azari P, Albers GW, et al. Spinal manipulative therapy is an independent risk factor for vertebral artery dissection. Neurology. 2003 May;60(9):1424-8. https://doi.org/10.1212/01.WNL.0000063305.61050.E6

15. Shin DH, Hong JM, Lee JS, Nasim R, Sohn SI, Kim SJ, et al. Comparison of potential risks between intracranial and extracranial vertebral artery dissections. Eur Neurol. 2014;71(5-6):305-12. https://doi.org/10.1159/000357867

16. Campos-Herrera CR, Scaff M, Yamamoto FI, Conforto AB. Spontaneous cervical artery dissection: an update on clinical and diagnostic aspects. Arq Neuropsiquiatr. 2008 Dec;66(4):922-7. https://doi.org/10.1590/S0004-282X2008000600036

17. Markus HS, Hayter E, Levi C, Feldman A, Venables G, Norris J; CADISS trial investigators. Antiplatelet treatment compared with anticoagulation treatment for cervical artery dissection (CADISS): a randomised trial. Lancet Neurol. 2015 Apr;14(4):361-7. https://doi.org/10.1016/S1474-4422(15)70018-9

18. Debette S, Grond-Ginsbach C, Bodenant M, Kloss M, Engelter S, Metso T, et al.; Cervical Artery Dissection Ischemic Stroke Patients (CADISP) Group. Differential features of carotid and vertebral artery dissections: the CADISP study. Neurology. 2011 Sep;77(12):1174-81. https://doi.org/10.1212/WNL.0b013e31822f03fc

19. Provenzale JM, Sarikaya B. Comparison of test performance characteristics of MRI, MR angiography, and CT angiography in the diagnosis of carotid and vertebral artery dissection: a review of the medical literature. AJR Am J Roentgenol. 2009 Oct;193(4):1167-74. https://doi.org/10.2214/AJR.08.1688

20. Engelter ST, Brandt T, Debette S, Caso V, Lichy C, Pezzini A, et al.; Cervical Artery Dissection in Ischemic Stroke Patients (CADISP) Study Group. Antiplatelets versus anticoagulation in cervical artery dissection. Stroke. 2007 Sep;38(9):2605-11. https://doi.org/10.1161/STROKEAHA.107.489666

21. Engelter ST, Traenka C, Von Hessling A, Lyrer PA. Diagnosis and treatment of cervical artery dissection. Neurol Clin. 2015 May;33(2):421-41. https://doi.org/10.1016/j.ncl.2014.12.002

22. Béjot Y, Daubail B, Debette S, Durier J, Giroud M. Incidence and outcome of cerebrovascular events related to cervical artery dissection: the Dijon Stroke Registry. Int J Stroke. 2014 Oct;9(7):879-82. https://doi.org/10.1111/ijs.12154 